\title{
MEASUREMENT OF THE EFFECTIVENESS STRATEGY IS/IT TO BUSINESS STRATEGY WITH IT BALANCED SCORECARD METHOD AT BINUS INTERNATIONAL JOSEPH WIBOWO CENTER
}

\author{
Hendy Wijaya ${ }^{1}$, Erny Carolina ${ }^{2}$ \\ ${ }^{1,2}$ Program Studi Sistem Informasi Universitas Bina Nusantara Jakarta, Indonesia \\ E-mail: hendy.wijaya@ binus.ac.id ${ }^{1}$,erny.carolina@yahoo.com ${ }^{2}$
}

Submission date: $2020-05-12$

Accepted date: 2020-05-22

\begin{abstract}
JWC is a campus line from Binus University that supports international standard management and business with the management of the academic development framework-EQUIS. To be able to work together and compete in a globalized world also requires the provision of operational facilities that are supported by the provision and management of information technology. The problem in this study is that companies are implementing an IS / IT strategy but not in accordance with their business strategy. If the strategy used cannot really be done, bankruptcy. The purpose of this research is to study whether the IS / IT strategy refers to the JWC business strategy. Measurement of the compatibility of the IS / IT strategy with this business strategy uses the IT Balance Scorecard, SWOT method to support strategic planning, and the Analytical Hierarchy Process method in determining the importance of interest. Data collection methods used were observation, interviews, literature study, questionnaires. The agreed outcome is an agreement consisting of the best IT SI SI strategy that supports JWC's business strategy.
\end{abstract}

Keywords: JWC. SI/TI Strategy, SWOT, Business.

\begin{abstract}
ABSTRAK
JWC merupakan lini kampus dari Binus University yang berfokus pada bidang manajemen dan bisnis yang berstandar internasional dengan pengelolaan academic development framework-EQUIS. Untuk mampu bekerja sama dan bersaing didunia global diperlukan juga penyediaan fasilitas operasional yang didukung oleh pemanfaatan dan pengelolaan teknologi informasi. Permasalahan dalam penelitian ini ialah perusahaan menjalankan strategi SI/TI namun tidak sesuai dengan strategi bisnisnya. Apabila strategi yang digunakan tidak benar bisa mengakibatkan kebangkrutan. Tujuan dari penelitian ini adalah untuk mengetahui apakah strategi SI/TI sejalan dengan strategi bisnis JWC. Pengukuran efektivitas strategi SI/TI terhadap strategi bisnis ini menggunakan metode IT Balance Scorecard, SWOT untuk mendukung penentuan strategi, serta metode Analytical Hierarchy Process dalam penentuan bobot kepentingan. Metode pengumpulan data yang dilakukan adalah observasi, wawancara, studi pustaka, kuisioner. Hasil yang dicapai adalah rekomendasi berupa insiatif strategi SI/TI yang terbaik untuk mendukung secara maksimal strategi bisnis pada JWC.
\end{abstract}

Kata Kunci: JWC. Strategi SI/TI, SWOT, Bisnis.

\section{PENDAHULUAN}

Binus International (JWC) merupakan salah satu kampus perguruan swasta yang menjadi bagian dari Yayasan binus. JWC menyediakan fasilitas terbaik bagi mahasiswanya. JWC terus melakukan pembelajaran, inovasi, dan pertumbuhan kedepan dengan dasar yang kuat, visi yang jelas dan kualitas yang baik. JWC selalu menjalankan misi-misinya untuk mencapai visi yakni menjadi "A World-class University In continuous pursuit of innovation and enterprise". Strategi bisnis memang merupakan langkahlangkah yang dilakukan perusahaan untuk mencapai visi-nya.
Salah satu hal yang digunakan untuk mendukung pencapaian visi tersebut adalah dengan penggunaan teknologi dalam menopang operasional perusahaan. Untuk itu, diperlukan pengembangan strategi SI/TI yang efektif sehingga inisiatif peningkatan kerja atau perubahan perusahaan dapat berhasil pada seluruh elemen perusahaan. Penelitian dari Mathius Tandiontong, Rajampi, dan Verani Carolina dengan judul Pengaruh Efektifitas Penerapan Metode Balance Scorecard Dalam Meningkatkan Kinerja Perusahaan. Metode penelitian yang digunakan dalam penelitian ini adalah metode deskriptif dengan pendekatan studi kasus serta metode statistik yang digunakan adalah metode statistik parametrik. 
Data diperoleh melalui penyebaran kuesioner terhadap manajer tingkat menengah dan juga staf divisi pada PT PLN (Persero) Distribusi Jabar dan Banten dengan sampel 20 orang. Penerapan metode balance scorecard atas jawaban responden yang dicapai untuk variabel $(\mathrm{X})$ yaitu pengaruh efektifitas penerapan metode balance scorecard pada PT PLN (Persero) Distribusi Jabar dan Banten, secara keseluruhan adalah 1586 dari skor maksimum 1900 atau mencapai $83.47 \%$. Jika melihat kriteria penilaian dapat disimpulkan bahwa pengaruh efektifitas penerapan metode balance scorecard adalah efektif (Tandiontong \& Carolina, 2011).

Penelitian dari R. Weddie Andriyanto \& Mega Metalia dengan judul Efektivitas Balanced Scorecard Dalam Maningkatkan Kinerja Manajerial Badan Usaha Milik Negara (BUMN). kinerja manajerial pada Badan Usaha Milik Negara (BUMN) yang telah menerapkan Balanced Scorecard lebih baik dibandingkan dengan BUMN yang menerapkan pengukuran kinerja tradisional. Model pengukuran kinerja dengan Balanced Scorecard menuntut perusahaan untuk mengukur kinerja dari empat perspektif, yaitu: perspektif keuangan, perspektif pelanggan, perspektif pertumbuhan dan pembelajaran serta perspektif proses bisnis internal. Sedangkan pengukuran kinerja tradisional hanya mengukur dari satu perspektif saja yaitu aspek keuangan. Oleh sebab itu, hasil penelitian ini menyarankan bahwa sebaiknya BUMN dapat segera menerapkan pengukuran kinerja dengan Balanced Scorecard agar kinerjanya dapat meningkat (Setiawan et al., 2017).

Penelitian dari Eldri Thesman dan I Gusti Bagus Rai Utama dengan judul Analisis Kinerja Menggunakan Balanced Scorecard (BSC). Balanced Scorecard berusaha untuk menerjemahkan misi dan strategi perusahaan ke dalam seperangkat ukuran secara menyeluruh, yang memberi penekanan pada pencapaian tujuan keuangan dan juga membuat faktor pendorong tercapainya tujuan keuangan tersebut. Balanced Scorecard memberikan rangka komprehensif untuk menjabarkan misi ke dalam sasaran-sasaran strategi. Sasaran-sasaran tersebut dapat dirumuskan karena balanced scorecard menggunakan empat perspektif yaitu: keuangan, pelanggan, proses bisnis internal, serta pembelajaran dan pertumbuhan. Perspektif keuangan akan menilai sasaran keuangan yang perlu dicapai organisasi dalam mewujudkan visinya. Perspektif pelanggan memberikan gambaran segmen pasar yang dituju serta tuntutan kebutuhan mereka dalam upaya untuk mecapai sasaran keuangan tertentu. Perspektif proses bisnis internal memberikan gambaran proses yang harus dibangun untuk melayani pelanggan dan untuk mencapai sasaran keuangan tertentu. Perspektif pembelajaran dan pertumbuhan merupakan pemacu untuk membangun kompetisi personel, prasarana sistem informasi dan suasana lingkungan kerja yang diperlukan untuk mewujudkan sasaran keuangan, pelanggan, serta proses bisnis internal (Thesman, 2015).

Salah satu cara menentukan strategi SI/TI adalah dengan mengidentifikasi kebutuhan dari setiap area bisnis. Secara singkat, cara yang terbaik dalam menentukan strategi SI/TI adalah dengan mengembangkan strategi SI/TI berjalan paralel dengan strategi bisnis. Akan tetapi, terkadang ditemukan perusahaan-perusahaan menjalankan strategi SI/TI namun tidak sesuai dengan strategi bisnisnya. Apabila strategi yang digunakan tidak benar bisa mengakibatkan kebangkrutan.

Tujuan dari penelitian ini adalah untuk mengetahui apakah strategi SI/TI sejalan dengan strategi bisnis JWC. Pengukuran efektivitas strategi SI/TI terhadap strategi bisnis ini menggunakan metode IT Balance Scorecard, SWOT untuk mendukung penentuan strategi, serta metode Analytical Hierarchy Process dalam penentuan bobot kepentingan.

Hal ini menjadi dasar mengapa penulis tertarik untuk melakukan evaluasi strategi SI/TI terhadap strategi bisnis dengan objek Binus university.

\section{METODE PENELITIAN}

Metode penelitian yang digunakan di dalam penelitian ini adalah metode studi pustaka dengan melakukan serangkaian tahapan yakni:

1. Menghimpun dokumen-dokumen yang diperlukan dalam melakukan penelitian mencakup buku, literatur, catatan, dan laporan terkait dengan masalah yang menjadi obyek penelitian,

2. Mempelajari dan menelaah dokumendokumen tersebut, dan kemudian

3. Mengumpulkan teori-teori relevan yang menunjang penelitian. Studi kepustakaan yang dilakukan meliputi dokumen tertulis maupun media elektronik.

Sebagai penelitian kepustakaan, maka terdapat dua macam sumber data yang dipaparkan: 
1. Sumber primer

Sumber primer dalam penelitian ini adalah SWOT dan IT Balanced Scorecard yang dijadikan sumber utama acuan peneltian (Kosasi, 2015).

\section{Sumber sekunder}

Sumber sekunder berupa buku, literatur, catatan, dan laporan pendukung dan pelengkap bagi sumber primer.

\section{Langkah Langkah Penelitian}

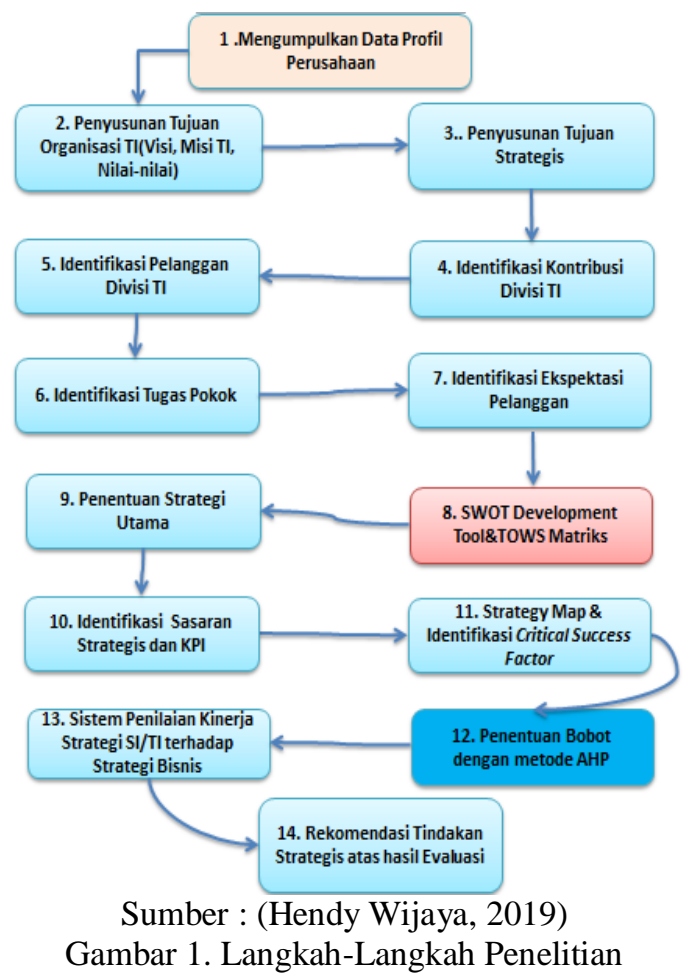

Langkah yang dilakukan dalam penelitian ini dari tahap awal hingga tahap akhir sebagai berikut :

1. Pada proses awal penulisan ini, dilakukan pengumpulan data berupa visi, misi, rencana jangka panjang, insiatif strategis, Academic Development Framework, peta strategis Balanced Scorecard, struktur divisi TI, arstitektur informasi berjalan, catatan mutu JWC, Stakeholder JWC serta data terkait kondisi dan tata kelola TI,. Kemudian berikutnya

2. Dilakukan langkah-langkah dalam penyusunan IT Balanced scorecard, tahap permulaan dilakukan penentuan tujuan organisasi TI yakni visi dan misi, nilai-nilai sebagai prinsip-prinsip yang melandasi tindakan dalam organisasi serta tahap selanjutnya (Wijaya, 2012).

3. Tujuan strategis divisi TI. Tahap 2 dan 3 ditentukan berdasarkan informasi yang telah dikumpulkan sebelumnya dan wawancara dengan Kepala TI mengenai tujuan kedepan divisi TI.

4. Mengevaluasi kembali kontribusi TI terhadap sasaran strategis perusahaan yang akan menjadi dasar dalam mengembangkan sasaran strategis lainnya. Kemudian dilakukan

5. Identifikasi pelanggan internal dan eksternal TI serta tugas pokok dari TI terhadap perusahaan

6. Sehingga didapat harapan dari identifikasi tugas pokok

7. Dari masing-masing kelompok stakeholder terhadap penggunaan TI dengan melakukan survei.

Kemudian untuk mengidentifikasi strategi utama dengan analisa SWOT sebagai dasar dari tindakan strategi lainnya dilakukan analisis lingkungan internal dan eksternal dengan menggunakan SWOT development tool yang berbentuk kuisioner yang diklasifikasikan kedalam kategori 4 perspektif IT BSC yang diisi oleh Kepala IT yang bertujuan untuk mengidentifikasi aspek internal dan eksternal TI melalui kekuatan, kelemahan, peluang dan ancaman pada divisi TI. Lingkungan internal mencakup struktur organisasi, proses dan prosedur, sumber daya manusia, sumber daya dan infrastruktur sedangkan lingkungan eksternal yaitu produk dan jasa yang disediakan divisi TI serta pasar dan pelanggan. Kemudian dilakukan penentuan strategi dengan tujuan meminimalisir kekurangan dan menangkap peluang yang dituangkan pada TOWS Matriks untuk menyusun formulasi strategis sehingga dapat diketahui tindakan-tindakan yang dapat dilakukan untuk mengakomodasi kelemahan dan juga menciptakan peluang baru dari kekuatan yang dimiliki dan ancaman yang mungkin terjadi (Rangkuti, 2005).

8. Dari formulasi strategis ini akan memperkuat penentuan pada strategi utama TI dan tindakan/ insiatif strategis

9. Langkah selanjutnya menentukan strategi utama

10. Menentukan sasaran strategis yang ditentukan berdasarkan strategi dan tujuan yang 
diturunkan oleh visi dan misi TI yang telah ditentukan pada proses 2, kemudian dilakukan penentuan pengukuran indikator kerja/ key performance indicator yang diturunkan dari operasional TI sebagai tolak ukur tingkat pencapaian setiap level aktivitas serta target yang ingin dicapai. Pada proses selanjutnya adalah digambarkan hubungan langsung antar perspektif kedalam peta strategis dan secara bersamaan dapat dilakukan identifikasi critical success factor.

11. Perusahaan, tujuan pada tahap ini adalah untuk membuat keputusan dalam menentukan variabel-variabel yang penting dan variabelvariabel yang kurang penting dalam mendukung tercapainya tujuan strategis.

12. Penilaian bobot masing-masing perspektif dan sasaran strategis secara mendetail dengan penggunaan metode Analytical Hierarchy Process, yang bertujuan untuk menghindari penilaian subjektif terhadap bobot penilaian. Tahap ini melibatkan penilaian bobot berdasarkan perspesi dari 2 pengambil keputusan yaitu Kepala IT dan IS Development Manager. Hasil dari tahap ini adalah bobot kepentingan secara spesifik.

13. Dilakukan tahap penilaian kinerja yang membandingkan realisasi dengan target, akan dilakukan proses evaluasi terhadap strategi SI/TI perusahaan dengan strategi bisnis dengan mempertimbangkan aspek-aspek penting yang terkait dengan metode IT BSC yakni corporate contribution, user orientation, internal/business process excellence, serta aspek orientasi kedepan(future orientation).

14. Proses yang terakhir adalah menentukan berapa lama waktu/ frekuensi dalam melakukan pengukuran kinerja selanjutnya dan penanggung jawab terhadap pengukuran tersebut serta memberikan rekomendasi berupa inisiatif strategis sebagai respon untuk memberikan tindakan terhadap realisasi/ pencapain skor yang telah didapat. Inisiatif strategis ini dibagi menjadi 2 bagian, yaitu langkah jangka pendek(kurun waktu 1-2 tahun) dan jangka menengah dan panjang (25 tahun).

\section{HASIL DAN PEMBAHASAN}

Pada tahap hasil pembahasan ini, dilakukan pengumpulan data berupa visi, misi, rencana jangka panjang, insiatif strategis, peta strategis Balanced Scorecard, serta data terkait kondisi dan tata kelola TI. Kemudian tahap selanjutnya dilakukan langkah-langkah dalam penyusunan IT Balanced scorecard, tahap permulaan dilakukan penentuan visi dan misi, nilai-nilai serta tujuan divisi TI.

Hal ini ditentukan berdasarkan informasi yang telah dikumpulkan sebelumnya dan wawancara dengan head of TI mengenai tujuan kedepan divisi TI.

Tahap selanjutnya adalah mengevaluasi kembali kontribusi TI terhadap sasaran strategis perusahaan yang akan menjadi dasar dalam mengembangkan sasaran strategis selanjutnya. Kemudian dilakukan identidikasi pelanggan internal dan eksternal TI serta tugas pokok dari TI sehingga didapat harapan dari masing-masing kelompok stakeholder terhadap penggunaan TI dengan melakukan survei.

Kemudian untuk mengidentifikasi sasaran strategis sebelumnya dilakukan analisis lingkungan internal dan eksternal dengan menggunakan SWOT development tool yang berbentuk kuisioner yang diklasifikasikan kedalam kategori 4 perspektif IT BSC yang diisi oleh Kepala IT yang kemudian diproses kedalam TOWS Matriks untuk menyusun formulasi strategis. Dari formulasi strategis ini akan memperkuat penentuan pada strategi utama TI. Langkah selanjutnya adalah menentukan sasaran strategis yang ditentukan berdasarkan strategi dan tujuan dari TI.

Ditentukan ukuran-ukuran KPI (key performance indicator) yang digunakan sebagai pengukur kinerja yang terbagi menjadi 2 macam ukuran Lag performance \& Lead Performance Indicator yang menjadi dasar dalam penentuan target dari divisi TI, dimana ditentukan berdasarkan sasaran strategis dan strategi utama TI.

Tahap selanjutnya adalah diidentifikasi hubungan sebab akibat antar perspektif yang digambarkan pada peta strategi dan diidentifikasi critical success factor dalam pencapaian tujuan TI JWC.

Setalah dilakukan penentuan sasaran strategis masing-masing perspektif kemudian dilakukan pembobotan masing-masing perspektif dan mendetil pada masing-masing indikator. 
Dilakukan metode AHP (analytical hierarchy process) yang melibatkan penilaian bobot berdasarkan perspesi dari 2 pengambil keputusan yaitu Kepala IT dan IS Development Manager. Hasil dari tahap ini adalah bobot kepentingan secara spesifik.

Setelah diketahui bobot kepentingan masing-masing indikator maka dilakukan penilaian terhadap kinerja operasional dengan melihat realisasi dan membandingkan dengan target. Hasil dari tahap ini adalah didapat total skor yang menunjukkan kondisi dari kinerja divisi TI. Hasil yang didapat adalah kinerja TI masuk kedalam kriteria sehat dimana divisi TI berperan penuh dalam pencapaian strategi bisnis.

Tahap terakhir adalah menentukan berapa lama waktu/ frekuensi dalam melakukan pengukuran kinerja selanjutnya dan penanggung jawab terhadap pengukuran tersebut, serta pada akhirnya adalah memberikan rekomendasi berupa inisiatif strategis sebagai respon untuk memberikan tindakan terhadap realisasi/ pencapain skor yang telah didapat. Inisiatif strategis ini dibagi menjadi 2 bagian, yaitu langkah jangka pendek(kurun waktu 1-3 tahun) dan jangka menengah dan panjang (3-5 tahun).

\section{Hasil dari penelitian ini sebagai berikut :}

1. Diidentifikasi sejumlah sasaran strategis untuk pencapaian tujuan oleh divisi TI yaitu:

- Perspektif corporate contribution yaitu "optimalisasi pemanfaatan anggaran TI", "tingkat kesesuaian proyek TI",

- User Orientation, yaitu "Terpenuhinya kebutuhan pengguna", "Peningkatan pengetahuan TI pengguna", "Tercapainya hubungan kerja industri",

- Operational Excellence, yaitu "Menjamin manajemen keamanan TI",

"Meningkatkan ketersediaan penggunaan dan pengembangan aplikasi", "Meningkatkan efektivitas dan efisiensi infrastruktur TI", "Keberhasilan proyek TI", "Meningkatkan kualitas layanan",

- Future Orientation,yaitu "Optimalisasi penggunaan dan pengembangan knowledge Management \& Organizational Capital", "Memaksimalkan sistem pengelolaan kinerja karyawan(KPI)", "Meningkatkan komptensi staff TI", "Mendorong penciptaan inovasi", "Meningkatkan motivasi kerja".

2. Dari tahapan proses pengukuran efektivitas strategi SI/TI yang didapat dari pengukuran kinerja dari sasaran strategis berdasarkan key performance indicator dapat disimpulkan divisi TI menjalankan strategi SI/TI dengan efektif dan memberikan kontribusi dalam pencapaian strategi bisnis dengan poin total pencapaian yaitu 86.19.

3. Untuk meningkatkan kontribusi dari divisi TI, maka direkomendasikan langkah jangka pendek, dan jangka panjang yang didasarkan pada hasil pengukuran efektivitas dengan metode IT BSC.

\section{KESIMPULAN}

Dari hasil yang kami dapatkan dari penelitian dan analisa yang telah dilakukan pada divisi TI Bina nusantara internasional JWC, maka dapat diambil beberapa kesimpulan dalam pengukuran efektivitas dengan metode IT Balanced scorecard terhadap strategi bisnis. Strategi-strategi utama TI untuk mendukung pencapaian strategi bisnis antara lain:

Berperan sebagai kontributor dalam pencapaian strategi bisnis melalui manajemen dan teknologi yang efektif (perspektif kontribusi perusahaan), Menjadi penyedia diferensiasi layanan dan produk TI (perspektif pengguna), Meningkatkan kualitas layanan TI dengan waktu dan biaya yang telah ditentukan (Perspektif operasional excellence), dan Meningkatkan kemampuan internal dan menciptakan inovasi guna kesiapan pada perubahan dan peluang masa depan (perspektif orientasi masa depan).

\section{DAFTAR PUSTAKA}

Hendy Wijaya, E. C. (2019). Measurement Of The Effectiveness Strategy Is/It To Business Strategy With It Balanced Scorecard Method At Binus International Joseph Wibowo Center.

Kosasi, S. (2015). Pengukuran Kinerja Web Brinet System Dengan Metode IT Balanced Scorecard. Jurnal Buana Informatika, 6(1). https://doi.org/10.24002/jbi.v6i1.403

Rangkuti, F. (2005). Analisis SWOT: Teknik Membedah Kasus Bisnis. Gramedia Pustaka Utama.

Setiawan, A., Andreswari, D., \& Coestera, F. F. (2017). GAP DAN PROFILE MATCHING UNTUK SELEKSI PENERIMAAN PENYIAR RADIO ( Studi Kasus PT Radio Swaraunib $F M$ ). 5(3), 249-259.

Tandiontong, M., \& Carolina, V. (2011). Pengaruh Efektifitas Penerapan Metode Balance Scorecard Dalam Meningkatkan Kinerja Perusahaan (Studi Kasus Pada PT PLN (Persero) Distribusi Jabar dan Banten). Maksi, 2. 
Thesman, E. (2015). Analisis Kinerja Menggunakan Balanced Scorecard (Bsc). July, $1-39$. https://doi.org/10.13140/RG.2.1.1278.7048

Wijaya, R. (2012). Analisis Model IT Menggunakan Balanced Scorecard Untuk Pengembangan Sistem Teknologi Informasi. Jurnal Sistem Informasi, 1-10. http://cls.maranatha.edu/khusus/ojs/index.ph p/jurnal-sistem-informasi/article/view/470 